\title{
Complementarities Between Universities and Technology Institutes: New Empirical Lessons and Perspectives
}

\author{
ANDRÉS BARGE-GIL*, LUIS SANTAMARÍA** \& \\ AURELIA MODREGO ${ }^{\dagger}$
}

*Department of Foundations of Economic Analysis (Quantitative Economics), Complutense University, Madrid, Spain, ${ }^{* *}$ Department of Business Administration, Carlos III University, Madrid, Spain, 'Laboratory for Analysis and Assessment of Technical Change, Carlos III University, Madrid, Spain

\begin{abstract}
This paper investigates the different roles played by universities and technology institutes (TIs) as innovation partners of firms. Comparing the characteristics of Spanish firms collaborating with these agents allows us to better define complementarities among the target groups of these organizations. Our findings show that those firms collaborating with universities are bigger, have higher internal capabilities and are less dependent on their external relationships while firms collaborating with TIs are smaller, have weaker internal capabilities but are more open to their environment and thus more reliant on external sources. We point to the implications of these findings for regional development. Universities have a role as partners of more technologically advanced firms. TIs, on the other hand, partner those firms, which though also quite advanced, require more external help in their innovation processes. These results should help policy-makers in the definition of more complex regional strategies and the provision of tools aimed at different goals. Managers of universities, TIs and client firms should find these results of help in developing more positive collaborations with one another.
\end{abstract}

\section{Introduction}

Firms' collaboration with external sources of knowledge has grown impressively in the last two decades (Charles \& Howells, 1992; Hagedoorn, 2002), which has increased the interest of academics and policy-makers in this area. On the side of government and policy-makers, several initiatives have been implemented to foster collaboration between firms and external sources of knowledge (Geroski, 1992; Martin, 1996). In the academic arena, several studies have tried to analyse the factors leading firms to collaborate with other organizations such as

Correspondence Address: Andrés Barge-Gil, Department of Foundations of Economic Analysis (Quantitative Economics), Complutense University, Madrid, Spain. Email: abarge@ccee.ucm.es 
suppliers, clients, competitors and research organizations (Fritsch \& Lukas, 2001; Cassiman \& Veugelers, 2002; Tether, 2002; Miotti \& Sachwald, 2003; Belderbos et al., 2004, among others). However, these empirical works have studied research organizations as a whole and do not distinguish among the characteristics of firms collaborating with a particular type of research organization such as a university, a public research organization (PRO) or a technology institute (TI). For example, Miotti and Sachwald (2003) consider collaborations with "public institutions" (collectively accounting for universities and PROs), while Cassiman and Veugelers (2002) label PROs, private research institutions and universities as "research institutions". Belderbos et al. (2004) in their study also lump together research institutions and universities. However, there are several differences among these various types of organization, which, in our opinion, have not been acknowledged.

Some authors have argued that they both differ and show complementarities (Galli \& Teubal, 1997; Smith, 1997; Beise \& Stahl, 1999; Fuellhart \& Glasmeier, 2003). The present study aims to shed more light on this type of research. More precisely, our main objective is to analyse the role of innovation partner to Spanish firms played by two types of research organizations: TIs and universities. The intention is to provide a better understanding of the potential complementarities between TIs and universities as innovation partners of firms. In particular, we are able to distinguish at least two dimensions of complementarity between Spanish universities and TIs: (i) collaboration with different types of firms and (ii) collaboration to fulfil different types of needs from the same firms. This distinction could be useful for policy-makers designing comprehensive regional development strategies, by providing specific tools addressed to different agents and goals. This work focuses on the first dimension of complementarity.

We also have two secondary objectives. First, we want to delve into the role played by TIs as innovation partners of firms. These types of organizations are found in the majority of developed countries and usually show a strong regional focus (Arnold et al., 1998; Koschatzky \& Sternberg, 2001; Molina-Morales \& Mas-Verdú, 2008), but have been rather ignored by the academic literature. Some examples of TIs in countries other than Spain include the Japanese Kosetsushi Centres, the US Manufacturing Technology Centres or the Italian Real Service Centres. Second, our analysis should help to clarify the role played by universities in territorial development, as innovation partners of firms. Of course, universities influence regional development via many channels (see, for example, Charles \& Howells, 1992; Cohen et al., 2002; Molas-Gallart et al., 2002; Goldstein \& Drucker, 2006), but it is their role as innovation partners that has been emphasized in recent years. Although a vast body of economic research has analysed universityindustry collaborations (Jaffe, 1989; Mansfield, 1991; Stephan, 1996; Narin et al., 1997; Henderson et al., 1998; Mowery et al., 2001; Agrawal \& Henderson, 2002, among others), these studies usually focus on a rather limited number of technological environments. Therefore, in order to understand differences among sectoral contexts, it is necessary to undertake large-scale cross-industry studies of university-industry collaborations (Laursen \& Salter, 2004; Perkmann \& Walsh, 2007) which should provide the opportunity to examine what factors influence the propensity of firms to draw on university research through collaborative projects (Klevorick et al., 1995).

We tackle with the issue of complementarities between universities and TIs and our two secondary objectives by analysing and comparing the characteristics of the two groups of firms: those that collaborate with TIs and those that collaborate with universities. ${ }^{1}$ We look particularly at the general characteristics of these firms (such as size, export behaviour and 
sector of activity), their innovation processes and their innovation results. The empirical analysis is conducted in two steps. First, we carry out an in-depth descriptive analysis and, second, we take an econometric approach using a random effects probit model. Data are from the Innovation Panel of the Spanish Institute of Statistics (2003-2004).

The paper is organized as follows. In the next section, we review the literature on the role of universities and TIs as innovation partners of firms. We then describe the data and the empirical strategy and go on to analyse our results. The final section provides a discussion of these results and our conclusions.

\section{Previous Studies and Open Debates}

\section{Universities as Technology Partners}

The role of universities as drivers of regional development has been widely analysed in the academic literature (Goldstein \& Drucker, 2006). The "third mission" of the university has been the subject of many recent studies through an approach within the "triple-helix" concept, which considers that nowadays regional development is based on interactions among three entities, universities, firms and public agencies, with each being a link in the same chain (Etzkowitz \& Leydesdorff, 1999, 2000). None of these spheres is prioritized; what is crucial is the convergence of communications, networks and organizations.

For these reasons, many OECD country governments have been supporting increased interactions between universities and industry (Cohen et al., 2002). These initiatives are often premised on the expectation that university-industry interactions can increase innovation rates in the economy (Spencer, 2001). Aggregate studies show that the influence of universities on private innovative outcomes of neighbouring firms is quite important (Jaffe, 1989), especially for small- and medium-sized enterprises (SMEs) (Acs et al., 1994; Feldman, 1994). These results are frequently interpreted according to the importance of face-to-face contacts to transfer tacit knowledge. However, none of these studies provides clarification on the channels involved in these interactions (Breschi \& Lissoni, 2001). This is rather important when we consider that the variety of these channels of influence is very high (Molas-Gallart et al., 2002). For example, not only joint projects between universities and firms but also training of graduates (Nelson, 1986; Narin et al., 1997), basic research (Feldman, 1994; Feller et al., 2002) and other activities have been highlighted as major ways that universities influence the productive sector.

There is another view that points to the formidable barriers to collaboration with universities for SMEs with weak internal research and development (R\&D) capacity (LawtonSmith, 1993) and which are a large proportion of productive sectors even in developed countries. These barriers exist because these firms usually do not know what are their real requirements, or have problems in expressing them (Lambrecht \& Pirnay, 2005), they do not know what types of complementary knowledge they need to develop innovations (Izushi, 2003) or which knowledge-intensive organizations have the most relevant capabilities (Charles \& Howells, 1992; Geisler, 1997; Teubal, 1997); they encounter difficulties when trying to communicate with them (Smallbone et al., 1993). The results of econometric studies corroborate this view. They agree that the firms that collaborate more with universities are larger firms which devote more internal efforts to R\&D and belong to high-technology sectors (Fritsch \& Lukas, 2001; Cassiman \& Veugelers, 2002; Miotti \& Sachwald, 2003; Belderbos et al., 2004). 
These problems imply that SMEs need support to be easily accessible and customized (Sánchez, 1999; Fuellhart \& Glasmeier, 2003), thus requiring a very active role of their partners in the knowledge-intensive sector, who need to help firms identify and articulate their needs. These knowledge organizations, therefore, must be proactive and develop knowledge about both their partners and the markets in which they operate. They must "speak the same language" as these firms (Smallbone et al., 1993). That is to say, they have to develop "technoeconomic" capabilities (Galli \& Teubal, 1997). However, it is very rare to find researchers in universities (or PROs) with the specific "technoeconomic" capabilities needed to implement successful collaborations with SMEs outside of the hightech sectors (Vickers \& North, 2001; Rolfo \& Calabrese, 2003). As a consequence, for traditional SMEs, the idea of using science inputs is foreign (Arnold \& Thuriaux, 1997).

Another factor that would explain some of the problems related to university-industry collaborations is that universities do not have sufficient incentive to collaborate with SMEs, and especially firms that are not technology- or science-based. Universities prefer to work with large firms because of their bigger financial resources and greater technological capabilities, which give reputation and the possibilities of future job offers (Charles \& Howells, 1992; Shapira et al., 1995; Hassink, 1997; Beise \& Stahl, 1999). In addition, although there is an increasing trend towards more applied research in universities, staff profiles are mainly purely scientific or technological (Rolfo \& Calabrese, 2003) and university researchers usually prefer to perform research rather become involved in development (del Barrio-Castro \& García-Quevedo, 2005). In relation to smaller universities, MacPherson and Ziolkowski (2005) have argued that they can become useful partners for local industrial firms if the object of the collaboration is relatively simple. Therefore, the debate over the role of universities is open and more evidence is needed on all these aspects.

\section{Specificities in the Role of TIs}

As has been noted, TIs exist in most developed countries and are important components of the regional and national knowledge infrastructure (Arnold et al., 1998; Mas-Verdú, 2007). They provide firms with a broader portfolio of services that differ from those offered by universities and private firms (Leitner, 2005). These research institutions focus not only on applied research and technology development, but also on activities such as consultancy, technical assistance, diagnosis and so on, thus reaching firms that otherwise would have no such support (Izushi, 2005). They can be public or privately owned and, although they usually receive public funding, private sources of funding are increasing (Leitner, 2005). Some examples of such organizations that in our view have been overlooked in the research literature are the Japanese Kosetsushi Centres, the USA Manufacturing Technology Centres, the Italian Real Service Centres and the Spanish TIs. ${ }^{2}$

The Spanish TIs are private, non-profit organizations that perform a wide range of knowledge-based activities oriented to enhancing firms' competitiveness. Most were created through joint efforts by private and public agents (mainly regional), which are represented on their board of directors. Some also have involvement of agents from the scientific community. They are key organizations in the Spanish National Innovation System because of their size and closeness to the productive sector (Modrego-Rico et al., 2005). There are around 100 TIs across Spain but their regional distribution is rather unequal. Some regions, such as País Vasco and Comunidad Valenciana, have more than 
15 TIs, which are well established (more than 10 years). Others, such as Castilla y León, have made efforts to increase the numbers and sizes of TIs in their territories in recent years. However, the technology policy of some regions has not been directed to supporting the establishment of TIs. There are regions with only one or two TIs, although interest in increasing their numbers is growing. Spanish TIs receive some $40 \%$ of their revenue from public bodies and the remaining $60 \%$ coming from contracts with the private sector, of which around $65 \%$ are related to $R \& D$ projects. These figures mean that the orientation of Spanish TIs to R\&D is higher than in the Japanese Kosetsushi Centres, the USA Manufacturing Technology Centres and the Italian Real Service Centres.

All these types of organizations, however, show some important differences when compared to universities. First, their main purpose is to increase the competitiveness of the firms; universities usually have a wider variety of objectives. Second, they offer a wide range of knowledge-intensive services, while universities mainly offer training, access to equipment and assistance on R\&D projects. Third, TIs' staffs have a wider focus. Rather than being completely centred on scientific aspects, TIs' staffs encompass knowledge about technology and generally also capabilities in management. Thus, they are able to offer "technoeconomic capabilities". Fourth, TIs are usually more immersed in the regional economy and their councils include relevant local stakeholders from both the public and private sectors. Universities are becoming more embedded in their local contexts, but there are still knowledge gaps which make interaction with local agents rather difficult. Fifth, TIs show flexible management procedures, in contrast to the bureaucracy of universities. For example, they do not have to publish calls subject to rigid administrative procedures to hire new staffs or to contract providers.

TIs are supposed to be important partners for supporting modernization and innovation activities of SMEs. However, there has been little research undertaken on this aspect and there are few studies that investigate the complementarities or redundancies among TIs and universities, an exception being Izushi (2005), which evaluates and compares the opinions of firms that cooperated in projects with both Kosetsushi Centres and universities. His results show that users rank the Kosetsushi Centres significantly higher in terms of their: (i) ability to perform the services promised; (ii) ability to communicate and (iii) ability to provide prompt services, but rate them as equal to universities in terms of the level of technical knowledge received by users.

Previous discussions about the role of universities and TIs as support organizations of firms' innovative efforts highlight the need for detailed empirical studies aimed at shedding light on the complementarities existing between them. In what follows, we will try to accomplish this task.

\section{Empirical Study}

\section{The Data}

Data on firms' characteristics come from the Innovation Panel of the Spanish Institute of Statistics for 2003 and $2004 .^{3}$ This database, which has only recently become available, is a very rich source of information on firms' innovation processes, although they are biased towards firms with internal innovation capabilities, which must be taken into account when interpreting the results. The sample includes 7283 firms with R\&D expenses and/ or which employ more than 200 people. In addition, 1437 were included in 2004. Of 
these firms, 438 had external but not internal R\&D expenditure and 999 firms with no recorded innovation expenses and fewer than 200 employees.

The data allow us to analyse the general characteristics of firms, such as size, export behaviour, ownership, sector of activity and the region in Spain where the R\&D department is located. But the main advantage is related to information on the innovation processes of firms which allows us to explore different features involved in their innovation efforts (innovation expenses and internal $\mathrm{R} \& \mathrm{D}$ activities), information sources, barriers to innovation and several innovation outputs. Moreover, we can distinguish the type of technological partner with which the firm has collaborated. In our study, we distinguish between TIs and universities. Table 1 presents the number of firms collaborating with them.

\section{Empirical Strategy}

The empirical objective is to compare the characteristics of two groups of firms: those collaborating with TIs but not with universities (TIs) and those collaborating with universities but not with TIs (universities). We should clarify that we are not trying to establish causal relationships, but rather to give a picture of the profiles of these two groups of firms and investigate their differences. We would expect this analysis to allow us to show complementarities among TIs and universities and to clarify their roles as innovation partners of Spanish firms. In order to explore firms' characteristics, we adopt an empirical strategy involving two steps. First, we describe the general characteristics, innovation processes and outputs of the firms. Second, we carry out an econometric analysis by means of a random effects probit model. As can be seen from Table 1, there are a group of firms that collaborate with both types of organization. The analysis of this group is not relevant to study the first dimension of complementarity, so that for clarity and simplicity, we did not include them in the general description.

For the descriptive analysis, we start with a study of the general characteristics of the firms in our sample, and especially economic aspects (such as income, number of employees and volume of exports), ownership information (if the firm belongs to a group and existence of foreign capital), sector of activity and the regional distribution of the firms' R\&D staff (as a proxy for the regional distribution of our sample). Next, we explore the different issues related to firms' innovation processes including innovation expenses, characteristics of internal R\&D activities (such as staff, type of R\&D and funding), sources of information and the main barriers to innovation activities. Finally, we explore several technological and organizational outcomes in terms of product and process innovations, industrial and intellectual property and some organizational innovations.

Alongside this descriptive analysis, where the variables are continuous, we employ two measures of centrality: mean and median values in order to avoid data from a minority of firms having disproportionate influence on our results. The median value best represents

Table 1. Firms collaborating only with TIs, only with universities or with both

\begin{tabular}{lcc}
\hline & 2003 & 2004 \\
\hline Collaborating only with TIs & 362 & 374 \\
Collaborating only with universities & 756 & 544 \\
Collaborating with both types of organization & 343 & 416 \\
\hline
\end{tabular}


the typical firm in each group. The $p$-values in the tables come from a two-sample $t$-test for equal means and for a $\chi^{2}$ test, respectively. In the case of median values, the $\chi^{2}$ test is performed taking into account the number of observations above and below the median in each group. Availability of data for 2 years (2003-2004) is an additional check of robustness because the firms in each group vary across years, while the characteristics of the

typical firm remain fairly stable. ${ }^{4}$ In addition, the econometric analysis (our second empirical step) will further add to the robustness of the firm characteristics in terms of their probability of cooperating with a TI or a university.

Where the variables are dichotomous (yes/no), we provide mean values which are between zero and one and could be interpreted as the percentage of firms collaborating with TIs or universities with the characteristics being considered (e.g. being an exporter, belonging to a group or a specific sector and achieving an innovation).

Three additional points related to the descriptive analysis require clarification. First, some of the tables provide data only for 2004 because, for certain items, firms were only asked about this year. Second, the ordinal variables are ranked from 1 (very important) to 4 (not important). This is the codification adopted by the Spanish National Institute, which we have retained. Third, the descriptive analysis is cross-sectional so that causalities should not be inferred from it, as some firm characteristics could be influenced by relationships developed with universities and TIs. But, having said this, it should be noted that the impact of the collaboration with TIs and universities usually emerges only in the medium or long term (Ham \& Mowery, 1998); thus, it would be unusual for it to become apparent in the period considered here.

\section{Results: Descriptive Analysis}

The descriptive results are presented in three subsections: (i) general characteristics (size, export activities and area of activity); (ii) innovation activities (strategies, innovation expenses and barriers to innovation) and (iii) results of the innovation process.

\section{General Characteristics}

Data from Tables 2 to 4 show that there exist sharp differences between the characteristics of firms collaborating with TIs and those collaborating with universities.

The mean and median values for income and number of employees show that firms collaborating with TIs are usually much smaller than those collaborating with universities (Table 2). However, there are changes across the 2 years. The mean and median sizes of firms increase for those collaborating with TIs but decrease slightly for those collaborating with universities. It is also interesting that the percentages of firms belonging to a group $^{5}$ and to a foreign multinational are higher for firms that collaborate with universities than for those that collaborate with TIs. Despite the differences in size and property, both the propensity to export and the export intensity (the percentage of income due to exports) are substantially higher among firms collaborating with TIs than among firms collaborating with universities.

The sectoral distribution of firms also varies (Table 3). We divided manufacturing into four sectors according to OECD (2005): low tech, low-medium tech, medium-high tech and high tech. ${ }^{6}$ Among the service sectors, we identified knowledge-intensive services. We can see that the percentage of firms in low-tech sectors is similar to firms collaborating 
Table 2. General characteristics of firms collaborating with TIs and universities

\begin{tabular}{|c|c|c|c|c|}
\hline & \multicolumn{2}{|c|}{2003} & \multicolumn{2}{|c|}{2004} \\
\hline & TIs & Universities & TIs & Universities \\
\hline \multicolumn{5}{|l|}{ Economic characteristics } \\
\hline Income (mean) $€$ & $29,800,000$ & $165,000,000^{* * *}$ & $40,500,000$ & $101,000,000^{* *}$ \\
\hline Income (median) $€$ & $5,450,458$ & $9,393,370^{* *}$ & $7,335,845$ & $8,933,048$ \\
\hline Number of employees (mean) & 154.57 & $530.04 * *$ & 197.03 & $418.72^{* * *}$ \\
\hline Number of employees (median) & 47.00 & $69.00^{* * *}$ & 57.00 & $61.5^{* * *}$ \\
\hline Exports (yes/no) & 0.64 & $0.59^{*}$ & 0.71 & 0.66 \\
\hline Exports/income (mean) & 0.33 & $0.29 *$ & 0.29 & 0.28 \\
\hline Exports/income (median) & 0.26 & $0.21^{*}$ & 0.20 & 0.18 \\
\hline \multicolumn{5}{|l|}{ Property } \\
\hline Group (yes/no) & 0.36 & $0.44^{* *}$ & 0.41 & 0.41 \\
\hline Foreign owned (yes/no) & 0.11 & $0.15^{*}$ & 0.10 & 0.12 \\
\hline
\end{tabular}

${ }^{*} p<0.1$.

${ }^{* *} p<0.05$.

${ }^{* * *} p<0.01$.

Table 3. Sector of activity of firms collaborating with TIs and universities

\begin{tabular}{|c|c|c|c|c|}
\hline & \multicolumn{2}{|c|}{2003} & \multicolumn{2}{|c|}{2004} \\
\hline & TIs & Universities & TIs & Universities \\
\hline \multicolumn{5}{|l|}{ Manufacturing } \\
\hline Low-tech sectors (yes/no) & 0.25 & 0.23 & 0.23 & 0.24 \\
\hline Low-medium-tech sectors (yes/no) & 0.30 & $0.14^{*}$ & 0.36 & $0.14^{*}$ \\
\hline Medium-high-tech sectors (yes/no) & 0.38 & 0.40 & 0.34 & 0.39 \\
\hline High-tech sectors (yes/no) & 0.07 & $0.23^{*}$ & 0.07 & $0.23^{*}$ \\
\hline \multicolumn{5}{|l|}{ Service sectors } \\
\hline Knowledge-intensive (yes/no) & 0.80 & $0.70^{*}$ & 0.71 & 0.69 \\
\hline Non-knowledge-intensive (yes/no) & 0.20 & 0.30 & 0.29 & 0.31 \\
\hline
\end{tabular}

${ }^{*} p<0.01$.

with TIs and universities. However, the percentage of firms in low-medium-tech sectors is higher among firms that collaborate with TIs than among those with universities, while, conversely, the percentage of firms in high-tech sectors is higher among those collaborating with universities.

Another characteristic of interest is where the firms are located. We do not have data on actual location, but we have information on the regional distribution of firms' R\&D staff based on workplace, which can be used as a proxy for firm location. Table 4 shows that firms collaborating with TIs have a higher percentage of R\&D employees in regions such as País Vasco, Comunidad Valenciana, Castilla y León, Navarra and La Rioja. The first four (together with Cataluña) are the regions with a highest number of TIs and La Rioja is geographically situated between País Vasco and Navarra, so our results fully support the importance of geographical proximity to TIs. Those firms collaborating 
Table 4. Regional distribution of R\&D staff of firms collaborating with TIs and universities

\begin{tabular}{lccccc}
\hline & \multicolumn{2}{c}{2003} & & \multicolumn{2}{c}{2004} \\
\cline { 2 - 3 } & TIs & Universities & & TIs & Universities \\
\hline \% Andalucía & 2.60 & $6.52^{* * *}$ & & 1.25 & $7.75^{* * *}$ \\
\% Aragón & 2.02 & $5.85^{* * *}$ & & 2.00 & $5.16^{* *}$ \\
\% Asturias & 3.09 & 2.18 & & 1.58 & 2.83 \\
\% Baleares & 0.28 & 0.55 & & 0.32 & 0.48 \\
\% Canarias & 0.56 & 0.54 & & 0.63 & 0.61 \\
\% Cantabria & 0.28 & $1.77^{* *}$ & & 0.32 & $1.64^{*}$ \\
\% Castilla y León & 7.94 & 5.80 & & 8.83 & 4.55 \\
\% Castilla La Mancha & 0.56 & $1.73^{*}$ & & 0.63 & 1.20 \\
\% Cataluña & 9.09 & $23.02^{* * *}$ & & 12.81 & $21.94^{* * *}$ \\
\% Comunidad Valenciana & 19.89 & $11.87^{* * *}$ & & 15.23 & $8.89^{* * *}$ \\
\% Extremadura & 0.56 & 0.83 & & 0.63 & 0.26 \\
\% Galicia & 5.41 & 7.70 & & 3.15 & $10.06^{* * *}$ \\
\% Madrid & 6.34 & $18.28^{* * *}$ & & 5.37 & $22.68^{* * *}$ \\
\% Murcia & 2.53 & 2.82 & & 0.95 & 2.47 \\
\% Navarra & 5.42 & 3.78 & & 7.07 & $3.08^{* * *}$ \\
\% País Vasco & 32.10 & $5.54^{* * *}$ & & 36.53 & $5.32^{* * *}$ \\
\% Rioja & 1.32 & 1.20 & 2.71 & $1.00^{*}$ \\
\% Ceuta y Melilla & 0.00 & 0.01 & 0.00 & 0.00 \\
\hline
\end{tabular}

${ }^{*} p<0.1$.

${ }^{* *} p<0.05$.

${ }^{* * *} p<0.01$.

with universities have a higher percentage of their R\&D staff in Madrid, Cataluña, Andalucía, Aragón, Cantabria, Castilla La-Mancha and Galicia.

\section{Innovation Activity}

This section investigates the innovation processes of each group of firms in terms of innovation expenses, ${ }^{7}$ internal $R \& D$ activities, type of research and funding, strategies used to access external knowledge and the barriers to innovation activities. These aspects are very revealing of the characteristics of firms' innovation processes, but some of them have rarely been exploited in the existing empirical studies.

Innovation expenses. Firms with higher innovation expenses (according to both mean and median) are those that collaborate with universities (Table 5). The same applies for innovation effort (innovation expenses/income), although wide disparities exist between mean and median values. Finally, the distribution of innovation expenses across different innovation activities (internal R\&D, external R\&D and non-R\&D activi$\operatorname{ties}^{8}$ ) shows that firms collaborating with TIs allocate a high proportion of their innovation expenses to external R\&D activities while those collaborating with universities are more focused on in-house R\&D. 
Table 5. Innovation expenses for firms collaborating with TIs and universities

\begin{tabular}{|c|c|c|c|c|}
\hline & \multicolumn{2}{|c|}{2003} & \multicolumn{2}{|c|}{2004} \\
\hline & TIs & Universities & TIs & Universities \\
\hline Innovation expenses (mean) $€$ & 687,000 & $2,299,038^{* *}$ & 657,703 & $1,968,888^{* * *}$ \\
\hline Median $€$ & 216,088 & $306,266^{* * *}$ & 203,139 & $274,000^{* *}$ \\
\hline Innovation expenses/income (mean) & 0.17 & 0.22 & 0.14 & $0.28^{* *}$ \\
\hline Innovation expenses/income (median) & 0.033 & 0.036 & 0.026 & 0.032 \\
\hline $\begin{array}{l}\text { Internal } \mathrm{R} \& \mathrm{D} / \text { total innovation } \\
\text { expenses (mean) }(\%)\end{array}$ & 75.20 & 76.81 & 67.15 & $75.70^{* * *}$ \\
\hline $\begin{array}{l}\text { External R\&D/total innovation } \\
\text { expenses (mean) }(\%)\end{array}$ & 16.47 & $12.72^{* * *}$ & 22.37 & $16.74^{* * *}$ \\
\hline $\begin{array}{l}\text { Other innovation expenses/total } \\
\text { innovation expenses (mean) }(\%)\end{array}$ & 8.34 & $10.47^{*}$ & 10.48 & $7.56^{* *}$ \\
\hline
\end{tabular}

Internal $R \& D$ activities. In line with previous results, we can see that the size of $\mathrm{R} \& \mathrm{D}$ staff is higher among those firms collaborating with universities than among those collaborating with TIs (Table 6). We can see that there are also differences in the type of R\&D performed reflected by the composition of $R \& D$ staff and $R \& D$ expenses. Firms collaborating with universities have higher percentages of researchers on their R\&D staff and are more oriented towards applied R\&D whereas firms collaborating with TIs employ a higher

Table 6. Internal R\&D of firms collaborating with TIs and universities

\begin{tabular}{|c|c|c|c|c|}
\hline & \multicolumn{2}{|c|}{2003} & \multicolumn{2}{|c|}{2004} \\
\hline & TIs & Universities & TIs & Universities \\
\hline \multicolumn{5}{|l|}{ R\&D staff } \\
\hline R\&D staff (mean) & 9.62 & $19.57^{* * *}$ & 9.41 & $18.16^{* * *}$ \\
\hline R\&D staff (median) & 5.00 & $7.00^{* * *}$ & 5.00 & $6.50^{* * *}$ \\
\hline \multicolumn{5}{|c|}{ Composition of R\&D staff by qualification } \\
\hline$\%$ Researchers & 46.59 & $50.28^{*}$ & 44.49 & $50.12^{* *}$ \\
\hline$\%$ Technicians & 31.86 & 32.49 & 33.70 & 33.44 \\
\hline$\%$ Assistants & 21.56 & $17.23^{* *}$ & 21.81 & $16.44^{* * *}$ \\
\hline \multicolumn{5}{|l|}{ Internal $R \& D$ expenses } \\
\hline$\%$ Basic research & 10.50 & 12.07 & 9.55 & 10.65 \\
\hline$\%$ Applied research & 29.53 & $44.08^{* * *}$ & 33.22 & $41.16^{* * *}$ \\
\hline$\%$ Technological development & 59.98 & $43.86^{* * *}$ & 57.23 & $48.19^{* * *}$ \\
\hline \multicolumn{5}{|l|}{ Funds for internal R\&D } \\
\hline$\%$ Own funds & 76.84 & $81.27^{* *}$ & 80.06 & 81.15 \\
\hline$\%$ Other Spanish firms' funds & 2.28 & 2.44 & 1.58 & 1.45 \\
\hline$\%$ Spanish public funds & 18.71 & $13.05^{* * *}$ & 15.42 & 13.77 \\
\hline$\%$ Foreign funds & 2.17 & 3.24 & 2.27 & 2.34 \\
\hline
\end{tabular}


percentage of research assistants and are more oriented to technological development activities. The way that R\&D is financed also differs. Firms collaborating with TIs make less use of internal financing and depend to a greater extent on public funding.

From the above results, it can be concluded that firms collaborating with TIs show a smaller internal research capacity which is reflected in the fact that: (i) they are smaller; (ii) they are less innovation-intensive; (iii) their innovation activities are less oriented to internal R\&D; (iv) their in-house R\&D is focused more on technological development (at the expense of applied research) and is performed by less well-qualified staff and (v) they have lower levels of internal financial resources to fund their R\&D activities and are more depending on regional and national public funding.

Sources of information. We have seen that firms that collaborate with TIs are much more oriented to external R\&D. In this section, we analyse the importance given by firms to different external sources of information. Firms were asked to rank them from 1 (very important) to 4 (not important) only in 2004.

The results in Table 7 show that firms collaborating with TIs are not only relatively more focused on external agents, but also, in absolute terms, generally assign more importance to them. These include suppliers, customers, competitors, consultants or R\&D firms and, coherently, TIs. Firms that collaborate with universities, on the other hand, assign more importance to universities and PROs.

Barriers to innovation activities. Again, firms were asked to rank the importance of different barriers to innovation activities from 1 (very important) to 4 (not important) only in 2004.

The main barriers to innovation are related to cost (Table 8). Firms consider innovation activities to be very expensive. They generally lack both internal funds and more especially external finance. These barriers apply equally to both groups of firms.

Table 7. Importance of sources of information (mean values) ${ }^{\mathrm{a}}$

\begin{tabular}{lcc}
\hline & \multicolumn{2}{c}{2004} \\
\cline { 2 - 3 } External sources of information & TIs & Universities \\
\hline Internal & 1.52 & 1.47 \\
Suppliers & 2.30 & $2.55^{* *}$ \\
Customers & 2.11 & $2.37^{* *}$ \\
Competitors & 2.60 & $2.77^{*}$ \\
Consultants or R\&D firms & 2.58 & $2.83^{* *}$ \\
Universities & 3.22 & $1.95^{* *}$ \\
PROs & 3.14 & $2.99^{*}$ \\
TIs & 1.96 & $3.20^{* *}$ \\
Conferences, markets and so on & 2.51 & 2.55 \\
Reviews & 2.62 & 2.52 \\
Professional and sectorial associations & 2.95 & 3.00 \\
\hline
\end{tabular}

${ }^{\text {a}}$ From 1 (very important) to 4 (non-important).

${ }^{*} p<0.05$.

${ }^{* *} p<0.01$. 
Table 8. Barriers to innovation activity in firms collaborating with TIs and universities (mean values) $^{\mathrm{a}}$

\begin{tabular}{lll}
\hline & \multicolumn{2}{c}{2004} \\
\cline { 3 - 3 } & TIs & Universities \\
\hline Cost factors & & 2.17 \\
Lack of internal funds & 2.10 & 2.13 \\
Lack of external funds & 2.11 & 2.08 \\
Innovation is very expensive & 2.05 & $2.76^{*}$ \\
Knowledge factors & & $2.80^{*}$ \\
Lack of qualified personnel & 2.49 & $2.83^{*}$ \\
Lack of information about technology & 2.61 & 2.74 \\
Lack of information about markets & 2.65 & 2.50 \\
Difficulties to find partners & & $2.40^{*}$ \\
Market factors & 2.41 & $3.58^{*}$ \\
Market is dominated by established firms & 2.18 & 3.55 \\
$\quad$ Uncertainty about new products & & 3.45 \\
Reasons for not being innovative & 3.47 & \\
There is no need, we have already innovated & & \\
There is no need, no demand for innovations exist & & \\
\hline
\end{tabular}

${ }^{\mathrm{a}}$ From 1 (very important) to 4 (non-important).

${ }^{*} p<0.01$.

However, there are clear differences in the barriers related to knowledge. Those firms collaborating with TIs rank lack of qualified personnel and information about technologies and markets as barriers to innovation more highly than firms collaborating with universities, which is in line with their lower levels of internal capabilities.

\section{Results of the Innovative Process}

This last section of descriptive results compares the outcomes of innovation activity from both a technological and an organizational viewpoint.

The probability of product or process innovation is similar among both groups of firms, with a slightly higher probability of process innovation for those collaborating with TIs in year 2004 (Table 9). The differences are sharper when we explore the way these innovations are achieved. Firms collaborating with TIs are more likely to achieve product and process innovations through external collaborations, while firms that collaborate with universities depend to a greater extent on their own efforts.

Tendency to apply for patents (data available only for 2003) is slightly lower among firms collaborating with TIs (Table 10) as is the number of patents by patenting firms. The number of national patents per patenting firm, however, is slightly higher for firms collaborating with TIs, while the number of US patents per patenting firm is significantly higher for firms collaborating with universities.

From an organizational point of view, there is greater dynamism among firms collaborating with TIs than among those collaborating with universities (Table 11) and especially in innovations related to management and strategy. ${ }^{9}$ 
Table 9. Product and process innovations of firms collaborating with TIs and universities

\begin{tabular}{|c|c|c|c|c|}
\hline & \multicolumn{2}{|c|}{2003} & \multicolumn{2}{|c|}{2004} \\
\hline & TIs & Universities & TIs & Universities \\
\hline \multicolumn{5}{|l|}{ Product innovation } \\
\hline Product innovation (yes/no) & 0.70 & 0.70 & 0.80 & 0.76 \\
\hline Own development (yes/no) & 0.80 & 0.84 & 0.58 & 0.61 \\
\hline Development in collaboration (yes/no) & 0.51 & $0.42^{*}$ & 0.40 & 0.38 \\
\hline External development (yes/no) & 0.02 & 0.04 & 0.02 & 0.01 \\
\hline \multicolumn{5}{|l|}{ Process innovation } \\
\hline Process innovation (yes/no) & 0.52 & 0.53 & 0.77 & $0.70^{*}$ \\
\hline Own development (yes/no) & 0.76 & 0.81 & 0.47 & $0.56^{*}$ \\
\hline Development in collaboration (yes/no) & 0.50 & 0.51 & 0.48 & $0.37^{* *}$ \\
\hline External development (yes/no) & 0.05 & 0.07 & 0.05 & 0.06 \\
\hline
\end{tabular}

${ }^{*} p<0.05$.

** $p<0.01$.

Table 10. Industrial and intellectual property in firms collaborating with TIs and universities

\begin{tabular}{|c|c|c|}
\hline & \multicolumn{2}{|c|}{2003} \\
\hline & TIs & Universities \\
\hline \multicolumn{3}{|l|}{ Industrial and intellectual property } \\
\hline Request a patent (yes/no) & 0.21 & 0.24 \\
\hline \multicolumn{3}{|l|}{ Number of patents } \\
\hline Number of patents (if patenting) & 3.23 & 3.99 \\
\hline Spanish & 2.45 & 2.21 \\
\hline European & 0.69 & 0.89 \\
\hline USA & 0.09 & $0.33^{*}$ \\
\hline
\end{tabular}

${ }^{*} p<0.1$.

Table 11. Organizational innovations by firms collaborating with TIs and universities

\begin{tabular}{lcc}
\hline & \multicolumn{2}{c}{2003} \\
\cline { 2 - 3 } & TIs & Universities \\
\hline Strategy (yes/no) & 0.42 & 0.37 \\
Management (yes/no) & 0.51 & $0.45^{*}$ \\
Organization (yes/no) & 0.49 & 0.45 \\
Marketing (yes/no) & 0.32 & 0.34 \\
Esthetical change (yes/no) & 0.43 & 0.42 \\
\hline
\end{tabular}

${ }^{*} p<0.05$. 


\section{Econometric Results}

Here we employ a random effects probit model to observe the influence of various firm characteristics on their probability to cooperate only with TIs or only with universities (Table 12). ${ }^{10}$ The goal is to check the robustness of the results obtained from the descriptive analysis. The dependent variable is a binary and takes the value 1 if the firm has collaborated with a TI and not with a university and 0 if it has collaborated with a university and not with a TI. Thus, as in the descriptive analysis, the econometric analysis is restricted to firms collaborating with one or other of these organizations.

We use a set of independent variables to represent the general characteristics and the innovation activity of firms. ${ }^{11}$

First, we consider the following general characteristics. Firm size (SIZE) is the number of employees in the firm. Firm sector is represented by six dummy variables, four of which correspond to the OECD's (2005) classification of manufacturing industries based on technology: high tech (HIGH TECH), medium-high tech (MEDIUM-HIGH TECH), medium-low tech (MEDIUM-LOW TECH), which is used as the control group, and low tech (LOW TECH). We also include two dummies for the service sectors, based on

Table 12. Results of the random effects probit model

\begin{tabular}{lccrc}
\hline $\begin{array}{l}\text { Number of observations }=1899 \\
\text { Number of groups }=1450\end{array}$ & & & & \\
Wald test of full model: $\chi^{2}=273.04$ & & & \\
\multicolumn{2}{l}{ Log pseudo-likelihood $=-876.35767$} & & & \\
\hline Ctvsuni & $\mathrm{d} F / \mathrm{d} x$ & Standard error & & $p>|z|$ \\
Size & -0.0004977 & 0.0001471 & -3.38 & $\mathbf{0 . 0 0 1}$ \\
Low tech & 0.3194373 & 0.2038964 & 1.57 & 0.117 \\
Medium-high tech & 0.9283436 & 0.2147018 & 4.32 & $\mathbf{0 . 0 0 0}$ \\
High tech & -0.6475293 & 0.2513671 & -2.58 & $\mathbf{0 . 0 1 0}$ \\
Kis & -0.2016077 & 0.2006675 & -1.00 & 0.315 \\
Nkis & -0.5409369 & 0.2710863 & -2.00 & $\mathbf{0 . 0 4 6}$ \\
R\&D_staff & -0.6634763 & 0.2705294 & -2.45 & $\mathbf{0 . 0 1 4}$ \\
Ex_R\&D & 0.0064218 & 0.0033603 & 1.91 & $\mathbf{0 . 0 5 6}$ \\
Techdev & 0.0075948 & 0.0016127 & 4.71 & $\mathbf{0 . 0 0 0}$ \\
\% Andalucía & -0.0020051 & 0.0038337 & -0.52 & 0.601 \\
\% Aragón & -0.0021416 & 0.0040501 & -0.53 & 0.597 \\
\% Asturias & 0.0077843 & 0.0046419 & 1.68 & $\mathbf{0 . 0 9 4}$ \\
\% Baleares & 0.0112887 & 0.0098314 & 1.15 & 0.251 \\
\% Canarias & 0.0153517 & 0.0080531 & 1.91 & $\mathbf{0 . 0 5 7}$ \\
\% Cantabria & -0.0089767 & 0.0073879 & -1.22 & 0.224 \\
\% Castilla y León & 0.0153417 & 0.0032254 & 4.76 & $\mathbf{0 . 0 0 0}$ \\
\% Castilla La Mancha & -0.0026459 & 0.0068372 & -0.39 & 0.699 \\
\% Cataluña & 0.0031995 & 0.0025233 & 1.27 & 0.205 \\
\% Comunidad Valenciana & 0.0155855 & 0.0026552 & 5.87 & $\mathbf{0 . 0 0 0}$ \\
\% Extremadura & 0.0110635 & 0.0084376 & 1.31 & 0.190 \\
\% Galicia & 0.0011853 & 0.0033181 & 0.36 & 0.721 \\
\% Murcia & 0.0044059 & 0.0046028 & 0.96 & 0.338 \\
\% Navarra & 0.0149534 & 0.00352 & 4.25 & $\mathbf{0 . 0 0 0}$ \\
\% País Vasco & 0.029471 & 0.0027739 & 10.62 & $\mathbf{0 . 0 0 0}$ \\
Rioja & 0.0145196 & 0.0057064 & 2.54 & $\mathbf{0 . 0 1 1}$ \\
\hline
\end{tabular}

${ }^{\mathrm{a} B o l d}$ characters are used when $p$-values are lower than 0.10 . 
the OECD (OECD, 2003) classification: knowledge-intensive services (KIS) and the nonknowledge-intensive services (NKIS). ${ }^{12}$ Finally, we include 17 variables for the region to which the firm belongs. In contrast to the usual regional dummies employed, our database allows us to use the percentage of total R\&D staff working in each of the 17 Spanish regions.

Second, we employ three indicators to represent intensity, type and openness of the firm's innovation activity. The intensity of innovation activity is proxied by the percentage of staff dedicated to R\&D activities (R\&D_STAFF), the type of R\&D activity is proxied by the percentage of $R \& D$ expenses oriented to development compared to that oriented to research (TECHDEV) and openness is proxied by the percentage of external R\&D expenses over total innovation expenses (EX_R\&D).

$\mathrm{d} F / \mathrm{d} x$ indicates the increment in the probability of collaborating with a TI instead of a university when each variable is incremented by one unit and the rest of the variables are fixed in their mean values. A positive ratio suggests that a higher value of the variable is associated with a higher probability of collaboration with a TI than with a university. $p>$ $|z|$ tests the probability of the coefficient of each variable being equal to zero. If $p>|z|$ is lower than 0.10 , we can conclude that the variable is significantly different from zero.

The results largely confirm those from the descriptive analysis. We found that firms collaborating with TIs are mainly located in regions with a high number of TIs, such as País Vasco, Comunidad Valenciana or Castilla y León. Technology policy in these three regions has clearly prioritized the establishment of these organizations. Thus, it seems that the focus of TIs is regional, which reinforces the results of other studies (ModregoRico et al., 2005; Barge-Gil \& Modrego-Rico, 2008).

Our results also agree with the findings from previous studies of bigger size and greater internal capacity of firms collaborating with universities. We were able to investigate this more deeply because of the richer data provided by our database. It is not only the sector of activity and $R \& D$ intensity that are important for interaction with universities but also the type of R\&D, in terms of the type of activities performed. The orientation of a firm's R\&D to research and the employment of researchers can facilitate mutual understanding in interaction with academia. On the other hand, it seems that firms collaborating with TIs display more relational capabilities, which is confirmed by their spending a higher percentage of their R\&D expenses on external R\&D.

\section{Discussion, Implications and Conclusions}

We investigated the complementarities among TIs and universities, focusing on the Spanish case and identifying one form of complementarity among them: collaborating with different types of firms. Our results provide some intuition about different profiles of each organization's partners. Firms collaborating with universities have better internal capabilities and seem to assign less importance to external relationships for innovation. Firms collaborating with TIs, however, have fewer internal capabilities, but are able to employ external resources to develop their innovation processes. This fact could be explained because those firms collaborating with universities perform the most important parts of their innovation activities internally and use their collaboration links for related activities, such as exploration of new knowledge that is far from the market, but not for the direct achievement of new products and processes (Feller et al., 2002). On the other hand, collaboration with TIs is much more oriented to the development of new products and processes. 
In terms of innovation results, the differences, although revealing, are not so sharp. Firms collaborating with TIs show similar tendencies to firms collaborating with universities in terms of product innovation and higher tendencies in relation to process innovations. They are also more dynamic from an organizational point of view in the sense that they are more likely to achieve managerial and strategic innovations. This last result could be interpreted as the facility of "technoeconomic" capabilities of TIs to generate organizational changes in firms (Oldsman, 1997; van Helleputte \& Reid, 2004), while universities tend to focus more on the technological or scientific arena.

Overall, these results suggest that, at least in Spain, universities are not so much focused on satisfying the needs of SMEs. In fact, our sample is biased towards firms with internal capabilities and, even among these firms, universities are less likely to collaborate with those with weaker scientific and technological internal resources. Our results show that TIs can play a role for these firms that may become crowded out of university partnerships, thus showing the complementarities that exist among them. Also, TIs seem to be more important to this group of firms than do universities to their partners. This can be explained by the arguments put forward in the literature review about the problems encountered by firms in exploiting the knowledge infrastructure and the importance of knowledge-intensive organizations in developing firms' "technoeconomic" capabilities in order to overcome these problems. ${ }^{13}$

Our findings have several important implications for scholars or policy-makers seeking to understand or promote regional economic development based on innovation. Previous works have highlighted the importance of the regional endowment of knowledge infrastructure (Lawton-Smith, 1993; Justman \& Teubal, 1995; Tödtling et al., 2006), but without differentiating between its various components, although some authors argue that they might differ and show complementarities (Smith, 1997; Beise \& Stahl, 1999; Vickers \& North, 2001; Fuellhart \& Glasmeier, 2003). In addition, the development of dense links with nearby firms was considered a precondition for their being effective, which does not always occur (Tödtling et al., 2006). We go a step beyond in two senses.

First, we go into the knowledge infrastructure and analyse the role played by two different organizations: universities and TIs, empirically showing that they are complementary. This allows us to give a more precise guide to policy-makers and managers. From a policy point of view, the recommendation would be not just to support the creation and development of infrastructure (in general), but also to provide support for a mix of organizations within this infrastructure because different organizations build links with different types of firms. From the point of view of managers, rather than considering the institutional infrastructure more broadly, they should focus on efforts to find the right partners. ${ }^{14}$

Second, we have investigated the characteristics of firms more relevant for linking with the organizations studied, thus providing a more specific orientation for policy-makers and managers. We find that the more advanced firms tend to collaborate with universities while firms with fewer (but still some) internal capabilities collaborate with TIs. We strongly agree with the view that in innovation policy a "one size fits all" approach is not adequate (Tödtling \& Tripp, 2005) and that policy initiatives should be more targeted and use different tools to focus on different groups of firms (Arnold \& Thuriaux, 1997; Smits \& Kuhlmann, 2004; Raymond et al., 2006). A detailed study of the characteristics of regional firms should be carried out before deciding on the proper weight of each organization in the knowledge infrastructure, and it is in this area that our findings should be of help. 
If this recommendation is ignored and an "ideal model" is applied, the probabilities of failure are very high (Tödtling \& Tripp, 2005). Nowadays, this ideal model seems to be focused on the central role played by universities in the territorial development (Smith, 2007). It is well known that their influence occurs through several channels (MolasGallart et al., 2002), but their role as innovation partners of firms has been emphasized, following the "triple-helix" approach (Leydesdorff \& Etzkowitz, 1996; Etzkowitz \& Leydesdorff, 2000). On the other hand, it has also been argued that the main role of universities in territorial development is in research (although this effect is complex and indirect) (Klevorick et al., 1995) and training of graduates (Faggian \& McCann, 2006). In this sense, our results provide evidence about the third mission of universities, which cannot be said to extend to the great majority of the productive sector but rather is focused on a minor proportion of firms with some specific characteristics, mainly good internal research capacities. Accordingly, we would argue that a policy that is focused too much on support for universities and their links with the productive sector, in regions where the majority of firms have not developed such capabilities, is, probably, a failed policy, in the sense that these links will not be established. In such circumstances, we would recommend a policy mix with a higher weight for some organizations with "technoeconomic" capabilities such as TIs.

It is important to note that although we adopt an organization-based perspective, what really matters are the functions that organizations perform rather than the organizations per se (Galli \& Teubal, 1997; Hekkert et al., 2008; Uyarra, 2010). From this point of view, our results show that, in Spain, universities and TIs fulfil quite different functions. This finding could likely be extended to other southern European countries such as Portugal or Greece (Charles \& Howells, 1992; Laranja, 2009). However, it is also true that in other institutional contexts, this difference would not exist (thus more empirical evidence is needed). However, what is crucial here is that different firms need different external capabilities and it is important that this variety exists within the knowledge infrastructure of the innovation system (regardless of which organizations provide them). If these capabilities are not available in the innovation system, it is possible that groups of firms could be crowded out of collaboration.

Our study has several limitations. Some are related to the characteristics of the database we drew on which is biased towards (i) big firms and (ii) R\&D-performing firms. Thus, we were not able to investigate the role played by TIs when collaborating with firms with weaker internal capabilities, which are a significant part of Spanish innovators (BargeGil et al., 2011). They presumably can play a more critical role for these firms. Also, the questions used in the survey that was the basis of our database follow the Oslo Manual (OECD, 1997, 2005) which means that we have to employ a somewhat fuzzy definition of collaboration, do not have information on issues such as what types of services are the subject of the collaboration and how many universities and TIs collaborate with each firm, their location and information specific to these relationships.

Finally, we think that our results suggest some directions for future research. First, it would be interesting to widen the analysis to firms with fewer internal technological capabilities, which do not undertake internal R\&D activities. Second, we have only analysed the first dimension of complementarity. We suggest that even when the same firm collaborates with universities and TIs, some degree of complementarity exists between what receives from each of these organizations. Third, we need to know more about the characteristics of the relationship between firms, TIs and universities. How does it start, what 
types of services are provided and in what volume, how does the relationship evolve, how is the service managed by both sides, etc. As standard surveys do not provide information on these issues, detailed case studies will be very informative. Fourth, we think that it would greatly advance our knowledge to have some direct measure of the impact of these relationships and to tackle the problem of their determinants from a holistic perspective that takes account of the characteristics of the firms, of the knowledge providers, of the relationships among them and of the environment in which the relationships occur.

\section{Notes}

1. Collaboration is defined as "active participation of the firm with universities and/or TIs in innovation activities. This does not include pure outsourcing (i.e. with no firm participation)". Note, however, that the collaborative relationship could include the provision of services if there is active participation by the firm. This distinction in innovation-related activities is quite fuzzy, because these types of activities usually demand the active participation of the client, so that difference between provision of services and innovation collaboration is usually a matter of degree rather than nature (Ham \& Mowery, 1998). It is also important to note that collaboration may imply bi-directional and reciprocal flows of knowledge.

2. There are other types of organizations in other countries, that are on the whole much bigger and more research-oriented, that originated in the public sector including the Fraunhofer Institutes, the Dutch TNO and Finland's VTT. The Spanish TIs are fairly heterogeneous and a few include some of the features (although on a smaller scale) of these larger organizations.

3. More information on the database can be found at http://sise.fecyt.es/Estudios/PITEC.asp (in English).

4. About $41.2 \%$ of firms cooperating only with TIs in 2004 were also cooperating only with TIs in 2003; $55 \%$ of firms cooperating only with universities in 2004 were also cooperating only with universities in 2003. This shows that for several firms cooperation is not a continuous strategy.

5. Belonging to a group does not imply being part of a multi-locational organization as the whole group might be located in the same place.

6. Low-tech industries include textiles, food products, tobacco, wood, paper products, among others. Lowmedium-tech industries include rubber and plastic products, coke, refined petroleum products, other nonmetallic mineral products, basic metals, among others. Medium-high-tech industries include electrical machinery, motor vehicles, chemicals excluding pharmaceuticals, railroad and transport equipment, machinery and equipment, among others. High-tech industries includes aircraft and spacecraft, pharmaceuticals, office machinery, radio, TV and computing machinery, medical, precision and optical instrument.

7. Innovation expenses include expenditure on both intramural and external R\&D and expenditure on other innovation-related activities such as acquisition of machinery, equipment and software (for the purposes of innovation), acquisition of other external knowledge (patents, licences, know-how and so on), training (specifically for the development of innovations), design and market introduction of innovations (OECD, 2005).

8. Acquisition of machinery, equipment and software, training, design, external knowledge (all aimed at innovation) and marketing of new products.

9. Innovations in management involve the implementation of new methods for organizing routines and procedures for the conduct of work. These include, for example, the implementation of new practices to improve learning and knowledge sharing within the firm. Innovations in strategy involve the implementation of a new or significantly changed corporate strategy. Mergers with, or the acquisition of, other firms are not included, even if a firm merges with or acquires another firm(s) for the first time.

10. We also performed a random effects probit model to analyse the characteristics of firms cooperating with both TIs and universities, which is available from the authors on request. These firms are the larger ones in the sample; those with higher internal capabilities and those more frequently belonging to the hightech sector.

11. We do not use any variable for firms' innovation results to avoid endogeneity problems in the regression. The same reasoning applies to the importance of the various sources of knowledge which is that innovation results in the period analysed could be affected by the collaboration with a TI or a university. Similarly, the importance given by the firm to each of these as a source of information would probably 
be affected by the characteristics of the links developed with them. Also, variables such as size could be argued to depend to some extent on collaboration with a TI or university. However, as previously mentioned, this link is more indirect and long term (Ham \& Mowery, 1998) so that it would be unusual for these effects to emerge within the period of initial collaboration.

12. Note that we have six different sectors; five are included in the regression and the sixth (medium-low tech) is used as the control group.

13. We should point out that although firms collaborating with TIs show lower levels of internal capacity based on the variables described above, they have more internal capabilities than the majority of Spanish firms. The data available do not provide enough information about less technology advanced firms; thus, we can only suggest that TIs are much more focused than universities on those advanced firms with the fewer internal technological capabilities.

14. The same applies to managers of universities or TIs.

\section{References}

Acs, Z., Audretsch, D. \& Feldman, M. (1994) R\&D spillovers and recipient firm size, The Review of Economics and Statistics, 76(2), pp. 336-340.

Agrawal, A. \& Henderson, R. (2002) Putting patents in context: Exploring knowledge transfer from MIT, Management Science, 48(1), pp. 44-60.

Arnold, E. \& Thuriaux, B. (1997) Developing Firms' Technological Capabilities, OECD Report, Brighton, Technopolis. Available at http://www.technopolis-group.com/resources/downloads/reports/094_Capabilities_ 970707.pdf (accessed 24 November 2010).

Arnold, E., Rush, H., Bessant, J. \& Hobday, M. (1998) Strategic planning in Research and Technology Institutes, $R \& D$ Management, 28(2), pp. 89-100.

Barge-Gil, A. \& Modrego-Rico, A. (2008) Are technology institutes a satisfactory tool for public intervention in the area of technology? A neoclassical and evolutionary evaluation, Environment and Planning C: Government and Policy, 26(4), pp. 808-823.

Barge-Gil, A., Nieto, M. J. \& Santamaría, L. (2011) Hidden innovators: The role of non-R\&D activities, Technology Analysis and Strategic Management, 23(4).

Beise, M. \& Stahl, H. (1999) Public research and industrial innovations in Germany, Research Policy, 28(4), pp. 397-422.

Belderbos, R., Carree, M., Diederen, B., Lokshin, B. \& Veugelers, R. (2004) Heterogeneity in R\&D cooperation strategies, International Journal of Industrial Organisation, 22(8-9), pp. 1237-1263.

Breschi, S. \& Lissoni, F. (2001) Knowledge spillovers and local innovation systems: A critical survey, Industrial and Corporate Change, 10(4), pp. 975-1005.

Cassiman, B. \& Veugelers, R. (2002) R\&D cooperation and spillovers: Some empirical evidence from Belgium, American Economic Review, 92(4), pp. 1169-1184.

Charles, D. \& Howells, J. (1992) Technology Transfer in Europe. Public and Private Networks (London: Belhaven Press).

Cohen, W., Nelson, R. \& Walsh, J. (2002) Links and impacts: The influence of public research on industrial R\&D, Management Science, 48(1), pp. 1-23.

Del Barrio-Castro, T. \& García-Quevedo, J. (2005) Effects of university research on the geography of innovation, Regional Studies, 39(9), pp. 1217-1229.

Etzkowitz, H. \& Leydesdorff, L. (1999) The future location of research and technology transfer, Journal of Technology Transfer, 24(2-3), pp. 111-123.

Etzkowitz, H. \& Leydesdorff, L. (2000) The dynamics of innovation: From National Systems and "Mode 2" to a Triple Helix of university-industry-government relations, Research Policy, 29(2), pp. 109-123.

Faggian, A. \& McCann, P. (2006) Human capital flows and regional knowledge assets: A simultaneous equation approach, Oxford Economic Papers, 58(3), pp. 475-500.

Feldman, M. (1994) The Geography of Innovation (Dordrecht: Kluwer Academic).

Feller, I., Ailes, C. \& Roessner, D. (2002) Impacts of research universities on technological innovation in industry: Evidence from engineering research centres, Research Policy, 26(3), pp. 317-330.

Fritsch, M. \& Lukas, R. (2001) Who cooperates on R\&D? Research Policy, 30(2), pp. 297-312.

Fuellhart, K. \& Glasmeier, A. (2003) Acquisition, assessment and use of business information by small- and medium-sized business: A demand perspective, Entrepreneurship and Regional Development, 15(3), pp. 229-252. 
Galli, R. \& Teubal, M. (1997) Paradigmatic shifts in national innovation systems, in: C. Edquist (Ed.) Systems of Innovation: Technologies, Institutions and Organisations, pp. 342-370 (London: Pinter Publishers).

Geisler, E. (1997) Intersector technology cooperation: Hard myths, soft facts, Technovation, 17(6), pp. 309-320.

Geroski, P. (1992) Antitrust policy towards co-operative R\&D ventures, Oxford Review of Economic Policy, 9(2), pp. 58-71.

Goldstein, H. \& Drucker, J. (2006) The economic development impacts of universities on regions: Do size and distance matter? Economic Development Quarterly, 20(1), pp. 22-43.

Hagedoorn, J. (2002) Inter-firm partnerships: An overview of major trends and patterns since 1960, Research Policy, 31(4), pp. 477-492.

Ham, R. M. \& Mowery, D. (1998) Improving the effectiveness of public-private R\&D collaboration: Case studies at a US weapons laboratory, Research Policy, 26(6), pp. 661-675.

Hassink, R. (1997) Technology transfer infrastructures: Some lessons from experiences in Europe, the US and Japan, European Planning Studies, 5(3), pp. 352-370.

Hekkert, M. P., Suurs, R. A. A., Negro, S. O., Kuhlmann, S. \& Smits, R. E. H. M. (2008) Functions of innovation systems: A new approach for analysing technological change, Technological Forecasting and Social Change, 74(4), pp. 413-432.

Henderson, R., Jaffe, A. \& Trajtenberg, M. (1998) Universities as a source of commercial technology: A detailed analysis of university patenting 1965-1988, Review of Economics and Statistics, 80(1), pp. 119-127.

Izushi, H. (2003) Impact of the length of relationships upon the use of research institutes by SMEs, Research Policy, 32(5), pp. 771-788.

Izushi, H. (2005) Creation of relational assets through the "library of equipment" model: An industrial modernization approach of Japan's local technology centres, Entrepreneurship and Regional Development, 17(3), pp. 183-204.

Jaffe, A. (1989) Real effects of academic research, The American Economic Review, 79(5), pp. 957-970.

Justman, M. \& Teubal, M. (1995) Technological infrastructure policy (TIP): Creating capabilities and building markets, Research Policy, 24(2), pp. 259-281.

Klevorick, A., Levin, R., Nelson, R. \& Winter, S. (1995) On the sources and significance of interindustry differences in technological opportunities, Research Policy, 24(2), pp. 185-205.

Koschatzky, K. \& Sternberg, R. (2001) R\&D cooperation in innovation systems-Some lessons from the European Regional Innovation Survey (ERIS), European Planning Studies, 8(4), pp. 487-501.

Lambrecht, J. \& Pirnay, F. (2005) An evaluation of public support measures for private external consultancies to SMEs in the Walloon region of Belgium, Entrepreneurship and Regional Development, 17(2), pp. 89-108.

Laranja, M. (2009) The development of technology infrastructure in Portugal and the need to pull innovation using proactive intermediation policies, Technovation, 29(1), pp. 23-34.

Laursen, K. \& Salter, A. (2004) Searching high and low: What types of firms use universities as a source of innovation? Research Policy, 33(8), pp. 1201-1215.

Lawton-Smith, H. (1993) Externalization of research and development in Europe, European Planning Studies, 1(4), pp. 465-482.

Leitner, K. (2005) Managing and reporting intangible assets in research technology organisations, $R \& D$ Management, 35(2), pp. 125-136.

Leydesdorff, L. \& Etzkowitz, H. (1996) Emergence of a triple helix of university-industry-government relations, Science and Public Policy, 23(5), pp. 279-286.

MacPherson, A. \& Ziolkowski, M. (2005) The role of university-based industrial extension services in the business performance of small manufacturing firms: Case-study evidence from Western New York, Entrepreneurship and Regional Development, 17(6), pp. 431-447.

Mansfield, E. (1991) Academic research and industrial innovation, Research Policy, 20(1), pp. 1-12.

Martin, S. (1996) Protection, promotion and cooperation in the European semiconductor industry, Review of Industrial Organization, 11(5), pp. 721-735.

Mas-Verdú, F. (2007) Services and innovation systems: European models of Technology Centres, Service Business, 1(1), pp. 7-23.

Miotti, L. \& Sachwald, F. (2003) Co-operative R\&D: Why and with whom? An integrated framework of analysis, Research Policy, 32(8), pp. 1481-1499.

Modrego-Rico, A., Barge-Gil, A. \& Núñez-Sánchez, R. (2005) Developing indicators to measure Technology Institutes' performance, Research Evaluation, 14(1), pp. 177-184.

Molas-Gallart, J., Salter, A., Patel, P., Scott, A. \& Duran, X. (2002) Measuring Third Stream Activities, Final Report to the Rusell Group of Universities, SPRU, University of Sussex. http://www.lse.ac.uk/ 
collections/CCPN/pdf/russell_report_thirdStream.pdf/russell_report_thirdStream.pdf (accessed

November 2010).

Molina-Morales, X. \& Mas-Verdú, F. (2008) Intended ties with local institutions as factors in innovation: An application to Spanish manufacturing firms, European Planning Studies, 16(6), pp. 811-827.

Mowery, D., Nelson, R., Sampat, B. \& Ziedonis, A. (2001) The growth of patenting and licensing by U.S. universities: An assessment of the effects of the Bayh-Dole act of 1980, Research Policy, 30(1), pp. 99-119.

Narin, F., Hamilton, K. \& Olivastro, D. (1997) The increasing linkage between U.S. technology and public science, Research Policy, 26(3), pp. 317-330.

Nelson, R. (1986) Institutions supporting technical advance in industry, American Economic Review, 76(2), pp. $186-189$.

OECD (1997) Oslo Manual: Proposed Guidelines for Collecting and Interpreting Technological Innovation Data, 2nd ed. (París: OECD Publications).

OECD (2003) Science, Technology and Industry Scoreboard (París: OECD Publications).

OECD (2005) Oslo Manual. Guidelines for Collecting and Interpreting Innovation, 3rd ed. (París: OECD Publications).

Oldsman, E. (1997) Manufacturing extension centres and private consultants: Collaboration or competition? Technovation, 17(5), pp. 237-243.

Perkmann, M. \& Walsh, K. (2007) University-industry relationships and open innovation: Towards a research agenda, International Journal of Management Reviews, 9(4), pp. 259-280.

Raymond, W., Mohnen, P., Palm, F. \& van der Loeff, S. (2006) A classification of Dutch manufacturing based on a model of innovation, De Economist, 154(1), pp. 85-105.

Rolfo, S. \& Calabrese, G. (2003) Traditional SMEs and innovation: The role of the industrial policy in Italy, Entrepreneurship and Regional Development, 15(3), pp. 253-271.

Sánchez, P. (1999) Política tecnológica para sectores tradicionales, Papeles de Economía Española, 81, pp. 242259.

Shapira, P., Roessner, D. \& Barke, R. (1995) New public infrastructures for small firm industrial modernization in USA, Entrepreneurship and Regional Development, 7(1), pp. 63-84.

Smallbone, D., North, D. \& Leigh, R. (1993) The use of external assistance by mature SMEs in the UK: Some policy implications, Entrepreneurship and Regional Development, 5(3), pp. 279-295.

Smith, K. (1997) Economic infrastructures and innovation systems, in: C. Edquist (Ed.) Systems of Innovation: Technologies, Institutions and Organisations, pp. 86-106 (London: Pinter Publishers).

Smith, H. L. (2007) Universities, innovation and territorial development: A review of the evidence, Environment and Planning C: Government and Policy, 25(1), pp. 98-114.

Smits, R. \& Kuhlmann, S. (2004) The rise of systemic instruments in innovation policy, International Journal of Foresight and Innovation Policy, 1(1-2), pp. 4-32.

Spencer, J. (2001) How relevant is university-based scientific research to private high-technology firms? A United States-Japan comparison, Academy of Management Journal, 44(2), pp. 432-440.

Stephan, P. (1996) The economics of science, Journal of Economic Literature, xxxiv(3), pp. 1199-1235.

Tether, B. (2002) Who cooperates for innovation, and why. An empirical analysis, Research Policy, 31(1), pp. 947-967.

Teubal, M. (1997) A catalytic and evolutionary approach to horizontal technology policies (HTPs), Research Policy, 25(8), pp. 1161-1188.

Tödtling, F. \& Trippl, M. (2005) One size fits all? Towards a differentiated regional innovation policy approach, Research Policy, 34(8), pp. 1203-1219.

Tödtling, F., Lehner, P. \& Trippl, M. (2006) Innovation in knowledge intensive industries: The nature and geography of knowledge links, European Planning Studies, 14(8), pp. 1035-1058.

Uyarra, E. (2010) What is evolutionary about "regional systems of innovation"? Implications for regional policy, Journal of Evolutionary Economics, 20(1), pp. 115-137.

van Helleputte, J. \& Reid, A. (2004) Tackling the paradox: Can attaining global research excellence can be compatible with local technology development? R\&D Management, 34(1), pp. 33-44.

Vickers, I. \& North, D. (2001) Regional technology initiatives: Some insights from the English regions, European Planning Studies, 18(3), pp. 301-318. 